\title{
Atividade antifúngica dos extratos de Luffa cilyndrica, Xanthosoma sagittifolium e Momordica charantia sobre Fusarium sp.
}

\author{
Jeislane Camila Sampietro Klack de Brito \\ Curso de Graduação em Agronomia. Universidade Federal da \\ Fronteira Sul Laranjeiras do Sul, PR, Brasil \\ Osmar da Rocha Levandoski Junior \\ E-mails: jeislanesampietro13@hotmail.com \\ levandoskijunior@hotmail.com \\ vanessa.silva@uffs.edu.br \\ Vanessa Gomes da Silva \\ kellersiqueira@hotmail.com \\ Amanda Keller Siqueira
}

Recebido em: 2 out. 2018. Aceito em: 7 dez. 2018.

DOI: http://dx.doi.org/10.21674/2448-0479.45.734-742

\section{Resumo}

Diversos estudos são desenvolvidos com o objetivo de buscar novas tecnologias, como a utilização de plantas alimentícias não convencionais no controle de fitopatógenos. O objetivo desta pesquisa foi avaliar o efeito de extratos vegetais de Luffa cilyndrica, Xanthosoma sagittifolium e Momordica charantia, em diferentes concentrações, sobre o crescimento micelial do fungo Fusarium sp. $\mathrm{O}$ procedimento foi realizado a partir dos extratos obtidos da maceração de folhas secas e moídas, incorporados ao meio de cultivo Batata Dextrose Ágar (BDA), nas concentrações de 0, 5, 15, 25 e $50 \%$. Subsequentemente, discos de papel-filtro contendo micélio de Fusarium sp. foram aplicados sobre o ágar e mantidos em estufa a $25{ }^{\circ} \mathrm{C}$. Após 48 horas de incubação, as avaliações foram realizadas em intervalos de 24 horas, permanecendo por sete dias, ou até o momento em que o micélio de Fusarium sp. da placa controle (0\%) alcançou os bordos da placa de Petri. O extrato de Xanthosoma sagittifolium a $50 \%$ e todas as concentrações do extrato de Momordica charantia, com exceção da 5\%, tiveram ação inibitória ao crescimento micelial de Fusarium sp., podendo ser consideradas alternativas diferenciadas e promissoras no controle do fitopatógeno.

Palavras-chave: PANCs. Fitopatógenos. Bucha. Taioba. Melão-de-são-caetano.

\section{Abstract}

\section{Antifungal activity of extracts of Luffa cilyndrica, Xanthosoma sagittifolium and Momordica charantia against Fusarium sp.}

Several studies have been developed aiming the discovery of new technologies, such as the use of unconventional food plants in the control of phytopathogens, The objective of this work was to 
evaluate the effect of plant extracts of Luffa cilyndrica, Xanthosoma sagittifolium and Momordica charantia, at different concentrations, on the mycelial growth of Fusarium sp. Dried and ground leaves were macerated and then supplemented into Potato Dextrose Agar (PDA) at 0, 5, 15, 25 and 50\% concentrations. Later, filter paper disks containing mycelium of Fusarium sp. were applied on the agar and incubated at $25^{\circ} \mathrm{C}$. After 48 hours of incubation, evaluations were performed every 24 hours, for seven days, or until the mycelium of Fusarium sp. in the control sample $(0 \%)$ reached the edges of the Petri dish. The extracts of Xanthosoma sagittifolium at $50 \%$ and all concentrations of Momordica charantia, except for the $5 \%$, had an inhibitory activity against Fusarium sp., and therefore those could be considered promising alternatives in controlling phytopathogens.

Keywords: UFPs. Phytopathogens. Sponge gourd. Tannia. Bitter gourd.

\section{Introdução}

Fungos do gênero Fusarium são responsáveis por diversas injúrias causadas em diferentes culturas, tornando-se um dos gêneros fúngicos mais estudados, pois afeta de forma negativa a economia, além de possuir ampla distribuição geográfica (O'DONNEL et al., 2013). Algumas espécies desse gênero sobrevivem em remanescentes culturais, por apresentar estruturas de resistência chamadas clamidósporos, resultantes de transformações de hifas, o que dificulta seu controle em diversas áreas. A infecção do patógeno inicia-se pelas raízes, através ou não de ferimentos. A colonização começa no sistema vascular, o que facilita a sua distribuição e reprodução por toda a planta, com crescimento de micélio e produção de conídios (AMORIM et al., 2011; DEAN et al., 2012).

O principal método de controle para esse fitopatógeno é o controle químico. Contudo, o uso de compostos químicos, a longo prazo, causa efeitos negativos aos seres humanos e demais animais, bem como para os ecossistemas. Ainda, o uso contínuo do controle químico como único método de controle pode resultar no aumento de populações de fitopatógenos resistentes ao uso de fungicidas. Nesse contexto, é imperativo que novas abordagens para o controle de fitopatógenos sejam desenvolvidas. Assim, um potencial método alternativo de controle de fitopatógenos, que apresenta custos e impactos ambientais reduzidos, é o uso de extratos brutos ou óleos essenciais extraídos a partir de diferentes espécies de plantas (CHAGAS et al., 2016; PINOTTI; SANTOS, 2013). Destaca-se o fato que o Brasil possui grande diversidade de vegetação, cujo potencial biotecnológico ainda é pouco explorado, apresentando uma carência de resultados acerca das potencialidades de uso dessas riquezas.

Nesse contexto, salienta-se que uma ampla variedade de espécies de plantas apresenta diversos princípios ativos antifúngicos em seus extratos com potencial aplicação tecnológica. Essas propriedades são relacionadas com uma série de fatores inerentes às plantas, principalmente partes vegetativas utilizadas, estádio fenológico e idade. A sua potencialidade depende da espécie envolvida, o tipo de patologia a ser controlada e das tecnologias utilizadas para extração e 
manipulação do extrato. A aplicação de extratos vegetais com ações antifúngicas poderá se estabelecer como uma alternativa agrícola viável, podendo complementar os métodos tradicionais de controle de fitopatógenos, além de ser uma forma ecológica, com reduzidos impactos para o ambiente (CHAGAS et al., 2016; VENTUROSO et al., 2011).

Entre as plantas que apresentam princípios ativos antifúngicos com potencial aplicação biotecnológica, destaca-se o grupo das plantas alimentícias não convencionais (PANCs), que são aquelas as quais ainda não existem estudos completos por parte da comunidade científica; que não são consumidas por um todo, além de não serem facilmente encontradas no comércio (BRASIL, 2010). Muitas delas são conhecidas devido ao uso medicinal e não alimentício (FLECK et al., 2015). Segundo Kinupp e Lorenzi (2014) existem cerca de 5.000 espécies de PANCs no Brasil e que além da sua importância na culinária e medicina, também são usadas em pesquisas para formulação de novos produtos. Apesar de diversos relatos destacarem a atividade antifúngica de extratos de plantas para diferentes espécies de fitopatógenos (CHAGAS et al., 2016; PINOTTI; SANTOS, 2013; VENTUROSO et al., 2011), ainda existe uma ampla variedade de espécies de plantas onde esse potencial biotecnológico foi pouco explorado para o controle de Fusarium sp.

Dentre as PANCs com potencial antifúngico, e que apresentam poucos estudos relacionados a esse potencial no controle de Fusarium sp., destacam-se as espécies melão-de-são-caetano (Momordica charantia L.), bucha (Luffa cylindrica L.) e taioba (Xanthosoma sagittifolium (L.) Schott). A atividade antifúngica de extratos de $M$. charantia e de $L$. cylindrica já foi relatada para o controle do desenvolvimento micelial de Fusarium solani L. (AHMAD e KHAN, 2011), enquanto o extrato de $M$. charantia foi promissor contra Colletotrichum musae (Berk. \& Curtis) Arx. (CELOTO et al., 2011), Fusariumsolani L. (WANG et al., 2016) e Fusarium oxysporum Schltdl. (GUPTA et al., 2016). Já Luffa acutangula L. inibiu o crescimento micelial de Colletotrichum gloeosporioides (Penz.) Penz. \& Sacc. (CELOTO et al., 2008). Para a espécie $X$. sagittifolium não foi observado na literatura científica consultada estudos que avaliassem o potencial antifúngico dessa espécie.

O objetivo do trabalho foi avaliar o efeito do extrato aquoso, em diferentes concentrações, de bucha vegetal, taioba e melão-de-são-caetano no crescimento micelial de Fusarium sp.

\section{Materiais e Métodos}

O experimento foi conduzido no Laboratório de Microbiologia, da Universidade Federal da Fronteira Sul (UFFS), Campus de Laranjeiras do Sul-PR. As partes aéreas das plantas bucha vegetal (L. cylindrica), taioba (X.sagittifolium) e melão-de-são-caetano (M.charantia) foram coletadas na cidade de Laranjeiras do Sul, nas coordenadas $25^{\circ} 24^{\prime} 28^{\prime \prime}$ S $52^{\circ} 24^{\prime} 58^{\prime \prime}$ W, e cadastradas no SisGen (número do cadastro AE26D84). O fungo Fusarium sp. (SisGen A87D2DB, UFFS-LS/21), utilizado no experimento, foi coletado e isolado também em Laranjeiras do Sul, e encontra-se preservado na micoteca do Laboratório de Fitopatologia da UFFS, Campus Laranjeiras do Sul.

As plantas foram coletadas na parte da manhã com o auxílio de uma tesoura e, em seguida, realizada a retirada de talos, flores e folhas danificadas por insetos ou doenças. Posteriormente 
procedeu-se a lavagem das folhas em água corrente, seguida de desinfestação com solução de hipoclorito de sódio a $10 \%$ por 20 minutos. Em sequência, o material foi lavado três vezes com água destilada para retirar o excesso da solução de hipoclorito. Subsequentemente, as partes aéreas das plantas foram colocadas sobre uma mesa forrada com papel absorvente, por 24 horas, para remover excesso de umidade.

Posteriormente, o material foi acondicionado em sacos de papel e colocado em estufa, com circulação forçada de ar, por 72 horas, a $40^{\circ} \mathrm{C}$. Após a secagem total o material foi moído em moinho de facas, armazenado em recipiente de vidro e mantido em condições laboratoriais até o momento do preparo dos extratos. A extração foi realizada a partir de maceração de $20 \mathrm{~g}$ de material vegetal preparado e $80 \mathrm{~mL}$ de água (20:80). O extrato aquoso foi obtido com a adição de água destilada fervente ao material seco, com posterior repouso de duas horas. Após este período, procedeu-se a filtragem em funil, contendo uma pequena porção de algodão como elemento filtrante. $O$ filtrado obtido foi então acondicionado em recipiente de vidro, embrulhado com papel alumínio para evitar a entrada de luz, e mantido em refrigerador a $4{ }^{\circ} \mathrm{C}$, até o momento da utilização.

Para a obtenção do micélio fúngico utilizado nos experimentos de inibição de crescimento micelial, Fusarium sp. foi cultivado em placas de Petri contendo Ágar Batata Dextrose (BDA) e mantido em estufa a $25^{\circ} \mathrm{C}$, por seis dias. No dia zero (0), ou seja, no primeiro dia do cultivo, foram aplicados discos estéreis de papel-filtro sobre a placa de BDA, em uma distância de aproximadamente $1 \mathrm{~cm}$ de onde o fungo foi cultivado, para que o crescimento micelial ocorresse sobre estes discos. Ao final dos seis dias propostos, os discos foram então removidos e utilizados nas placas controle e nas placas acrescidas de extrato.

Para os ensaios de inibição do crescimento micelial de Fusarium sp., ao meio de cultivo BDA foram acrescidos extratos das PANCs nas concentrações $0,5,15,25$ e $50 \%$ e, posteriormente, a mistura foi esterilizada a $120^{\circ} \mathrm{C}$, por 20 minutos. Após o preparo das placas de Petri, estas passaram por controle de esterilidade $\left(24\right.$ horas em estufa a $35^{\circ} \mathrm{C}$ ), para garantir a ausência de microrganismos contaminantes. Os tratamentos controles foram representados pelo cultivo dos discos contendo micélio fúngico em BDA.

Posteriormente, os discos de Fusarium sp.foram transferidos para as placas de Petri contendo BDA adicionado das diferentes concentrações dos três extratos, individualmente, e incubados em estufa a $25{ }^{\circ} \mathrm{C}$. As avaliações iniciaram-se após 48 horas de incubação, com repetições a cada 24 horas, permanecendo por sete dias, ou até que o micélio de Fusarium sp. da placa controle atingisse o bordo da placa de Petri. O parâmetro analisado foi estabelecido na determinação da média do diâmetro diário da colônia, em duas posições perpendiculares entre si, de acordo com a metodologia proposta por Celoto (2005).

O delineamento experimental empregado foi o inteiramente casualizado, constituído do isolado de Fusarium sp., de 13 tratamentos, extrato de três plantas (bucha vegetal, taioba e melãode-são-caetano), quatro concentrações $(5,15,20$ e 50\%, em relação ao volume), dos controles (BDA puro $-0 \%$ ) e em quatro repetições. 
Os resultados foram submetidos à análise de variância e em caso de significância as médias foram comparadas pelo teste Tukey a $5 \%$ de probabilidade, e análise de regressão.

\section{Resultados e Discussão}

Os extratos de bucha vegetal demonstraram, em todas as avaliações, não possuir atividade antifúngica sobre o patógeno, pois na maior parte do experimento, o crescimento micelial do fungo em presença da bucha foi maior do que na placa contendo apenas BDA (Tabela 1).

Tabela 1 - Efeito de diferentes concentrações do extrato de bucha vegetal (Luffa cylindrica) no crescimento micelial de Fusarium sp., medido em milímetros, em cinco dias de avaliações.

\begin{tabular}{|c|c|c|c|c|c|}
\hline & Dia 1* & Dia 2* & Dia 3* & Dia 4* & Dia 5* \\
\hline Controle & $32,25 \pm 0,96^{a}$ & $46,00 \pm 0,82^{a}$ & $59,00 \pm 0,82^{b}$ & $70,75 \pm 0,96^{b}$ & $90,00 \pm 0,00^{a}$ \\
\hline Bucha 5\% & $32,75 \pm 2,22^{a}$ & $48,13 \pm 1,18^{a}$ & $63,38 \pm 0,63^{a}$ & $74,88 \pm 0,48^{a}$ & $90,00 \pm 0,00^{a}$ \\
\hline Bucha 15\% & $33,13 \pm 1,25^{a}$ & $46,25 \pm 0,65^{a}$ & $62,13 \pm 0,75^{a b}$ & $70,75 \pm 0,87^{b}$ & $90,00 \pm 0,00^{a}$ \\
\hline Bucha 25\% & $31,13 \pm 1,11^{a}$ & $48,13 \pm 2,43^{a}$ & $59,88 \pm 1,44^{\text {ab }}$ & $73,38 \pm 2,02^{a}$ & $90,00 \pm 0,00^{a}$ \\
\hline Bucha $50 \%$ & $33,38 \pm 0,25^{a}$ & $49,13 \pm 2,10^{a}$ & $63,63 \pm 3,50^{a}$ & $74,00 \pm 0,58^{a}$ & $90,00 \pm 0,00^{a}$ \\
\hline $\mathrm{CV}^{* *}(\%)$ & 4,05 & 3,36 & 2,90 & 1,54 & 0 \\
\hline
\end{tabular}

*Valores que apresentam a mesma letra, em uma coluna, não diferem estatisticamente entre si. Foi aplicado o Teste de Tukey ao nível de $5 \%$ de probabilidade. ${ }^{* *}$ CV: coeficiente de variação.

Fusarium sp. é considerado cosmopolita em sua ocorrência, sendo descrito como importante causador de diversas patologias em plantas, incluindo a bucha. Silva et al. (2012) descreveram ocorrência relevante deste fitopatógeno em bucha comestível, o que pode explicar os resultados negativos com o uso de extrato aquoso de bucha vegetal na inibição do crescimento micelial de Fusarium sp. observados neste estudo. Ao contrário, pesquisas realizadas no Paquistão revelaram atividade antifúngica significativa de Luffa sp. contra Fusarium sp. (AHMAD; KHAN, 2013).

Nos experimentos de inibição de crescimento micelial de Fusarium sp. utilizando extrato aquoso de taioba, apenas a concentração $50 \%$ revelou atividade antifúngica em todos os dias de incubação, já com maior efeito inibitório a partir o segundo dia de avaliações em comparação com a placa controle (Figura 1). 


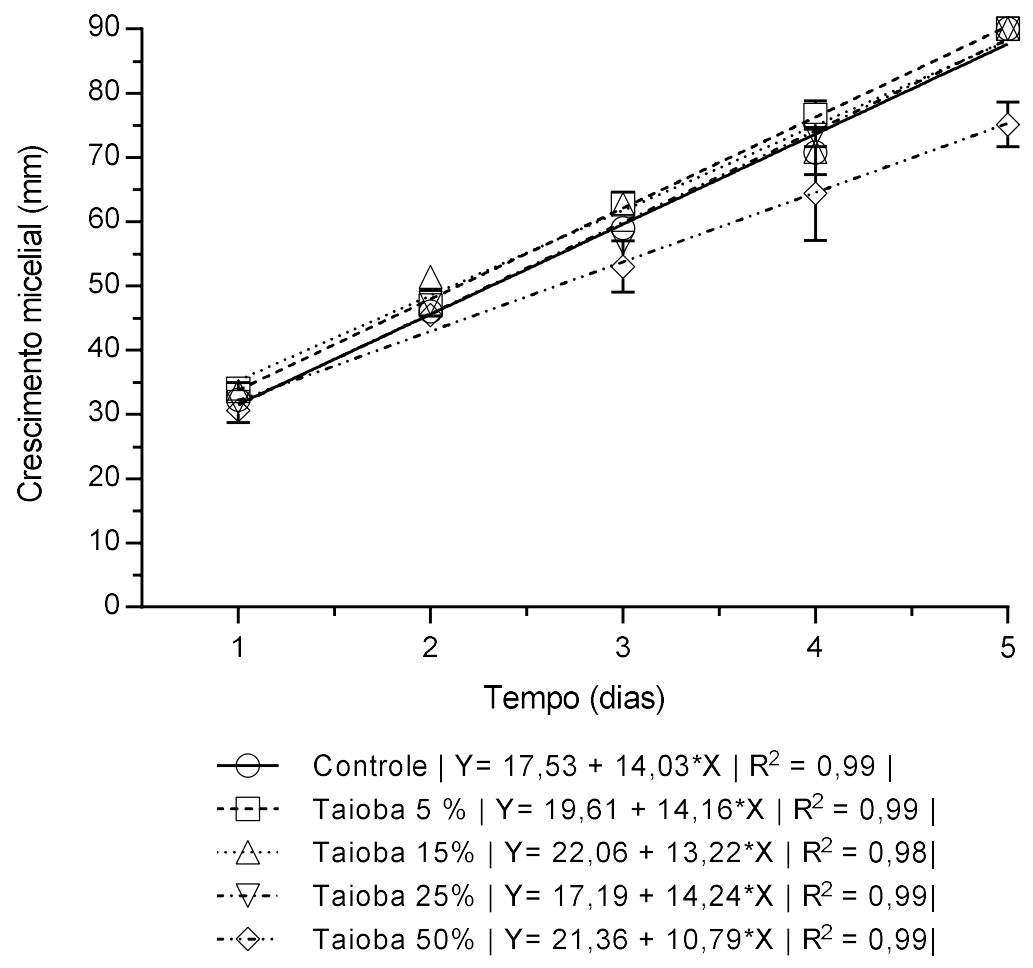

Figura 1 - Crescimento micelial de Fusarium sp. sob a ação de taioba (X. sagittifolium), medido em milímetros, em cinco dias de avaliações.

Os resultados desta pesquisa poderiam trazer uma opção barata e sustentável de controle de Fusarium sp., no entanto, a elevada concentração de extrato de taioba $(50 \%)$ necessário para a inibição de apenas $17 \%$ de crescimento micelial do fungo avaliado (Figura 1) pode ser fundamentada no fato de que diferentes espécies de Fusarium são patogênicas para Xanthosoma sp., ocasionando a doença da podridão radicular. Esta enfermidade é considerada importante, principalmente nos países com hábito de consumo desta PANC, como Nigéria e Indonésia (AGU et al., 2014; WIDODO; SUPRAMA, 2011).

O extrato aquoso de melão-de-são-caetano, nas concentrações 15,25 e $50 \%$, foi efetivo. A inibição do crescimento micelial de Fusarium sp. foi observada desde o primeiro até o quinto dia, sendo estatisticamente diferente da placa controle. No segundo dia de incubação foi verificada a superioridade desses extratos, onde a inibição do crescimento micelial variou de 39 a $48 \%$ proporcionalmente a placa controle (100\%) (Figura 2). Observando-se a figura 2 também pode-se notar que o extrato aquoso de melão-de-são-caetano a $15 \%$ causou redução mais expressiva de crescimento micelial do fungo, podendo ser considerada a menor concentração inibitória $(47,77 \%)$ "in vitro" promissora para uso com antifúngico. 


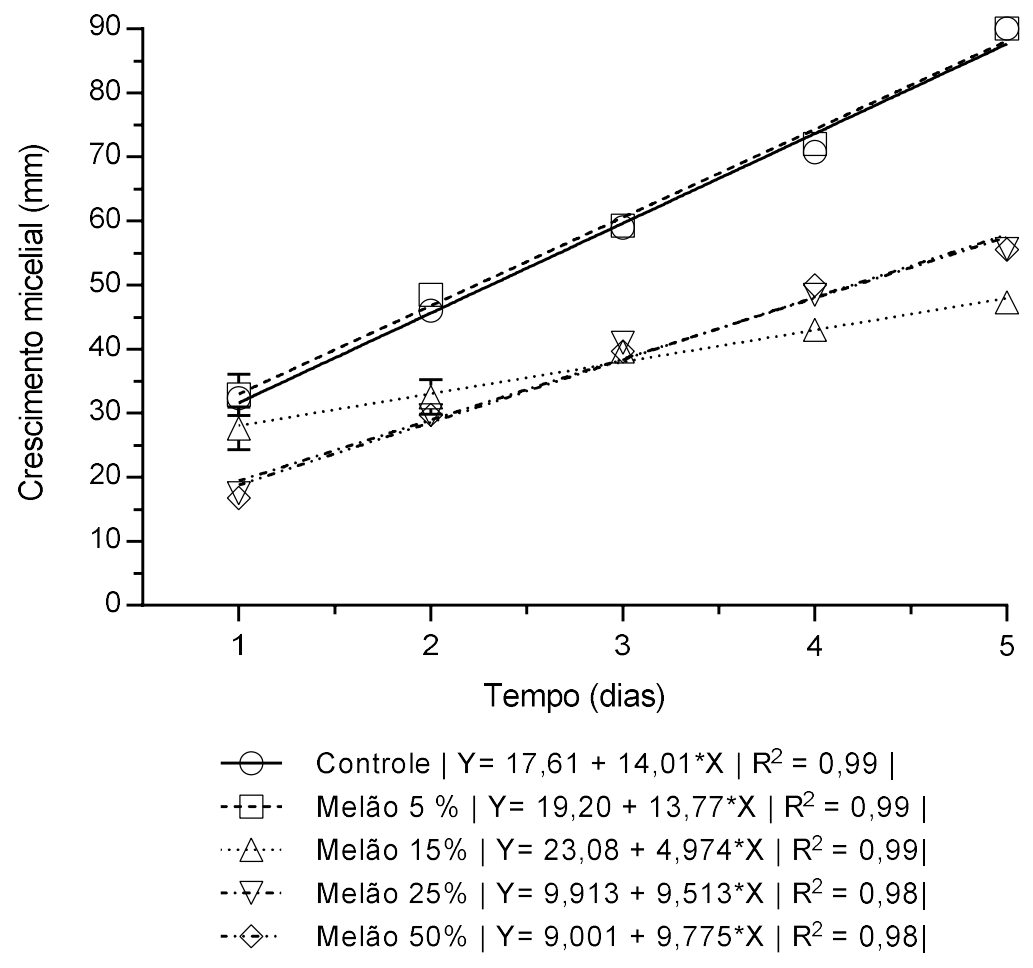

Figura 2 - Crescimento micelial de Fusarium sp. sob a ação de melão-de-são-caetano (M. charantia), medido em milímetros, em cinco dias de avaliações.

Em consonância com esta pesquisa, diferentes trabalhos revelaram efetividade de Momordica charantia no biocontrole de fitopatógenos como Fusarium sp. (AHMAD; KHAN, 2013; GUPTA et al., 2016; ZHU et al., 2018; WANG et al., 2016). Além do mais, esta PANC também apresenta atividade inibitória sobre outros fitopatógenos como descrito por Celoto et al. (2008), que utilizando extratos de melão-de-são-caetano em uma concentração de $20 \%$, sobre o fungo Colletotrichum gloeosporioides, observaram que houve a inibição de mais de $90 \%$ do micélio do patógeno. Em pesquisa subsequente, Celoto et al. (2011) utilizaram extrato aquoso de melão-de-sãocaetano no controle de Colletotrichum musae e descreveram que o extrato a $50 \%$ proporcionou $71 \%$ de inibição de crescimento micelial do fitopatógeno utilizado. Os estudos desenvolvidos ao longo dos anos demonstram que o extrato de melão-de-são-caetano é potencialmente viável no controle de diferentes fitopatógenos.

Proteínas inativadoras de ribossomos (RIPs - "ribosome inactivating proteins"), como lufacilina, isolada de L. cylindrica, e alfa ou beta-momorcarina, de M. charantia, foram descritas com alta atividade antifúngica contra Fusarium sp. (ZHU et al., 2018), o que aponta para a necessidade de extração e isolamento das substâncias descritas acima e realização de ensaios "in vitro". Ademais, na literatura consultada não foi possível encontrar relatos de substâncias responsáveis pela atividade antifúngica de $X$. sagittifolium.

Fungicidas e extratos de plantas utilizados contra fungos fitopatogênicos têm sido comparados em seu modo de ação por décadas. Comprovadamente, os produtos naturais 
representam alternativas sustentáveis ao uso de produtos sintéticos (WANG et al., 2016). De acordo com Celoto et al. (2008), as plantas com efeito inibidor ao desenvolvimento de fitopatógenos poderiam ser diretamente empregadas pelos produtores rurais, tanto através de cultivo consorciado, quanto com o uso de solução aquosa, bem como, a partir das RIPs identificadas, novos produtos poderiam ser sintetizados pela indústria de produtos naturais.

Assim exposto, há a necessidade de estudos de varredura para a determinação de substâncias com potencial antifúngico a partir de taioba e posterior empregabilidade das substâncias isoladas de bucha, melão-de-são-caetano e taioba em estudos clínicos para o controle de fungos fitopatogênicos.

\section{Conclusão}

As concentrações 15,25 e $50 \%$ de extrato de melão-de-são-caetano e de taioba a $50 \%$ podem ser consideradas alternativas diferenciadas e promissoras no biocontrole de Fusarium sp ${ }^{1}$.

\section{Referências}

AGU, K. C. et al. Identification and pathogenicity of rot-causing fungal pathogens associated with Xanthosoma sagittifolium spoilage in south eastern Nigeria. Int. J. Agric. Innovations Res., v. 2, p. 1155-1159, 2014.

AHMAD, B.; KHAN, A. A. Antibacterial, antifungal and phytotoxic activities of Luffa cylindrica and Momordica charantia. J. Med. Plants Res., v. 7, p. 1593-1599, 2013.

AMORIM, L.; REZENDE, J. A. M.; BERGAMIN FILHO, A. Manual de fitopatologia: princípios e conceitos. 4. ed. Piracicaba: Agronômica Ceres, 2011.

BRASIL. Ministério da Agricultura, Pecuária e Abastecimento. Manual de hortaliças não convencionais / Ministério da Agricultura, Pecuária e Abastecimento. Secretaria de Desenvolvimento Agropecuário e Cooperativismo. Brasília: Mapa/ACS, 2010.

CELOTO, M. I. B. et al. Atividade antifúngica de extratos de Momordica charantia L. sobre Colletotrichum musae. Rev. Bras. Plantas Med., v. 13, p. 337-341, 2011.

CELOTO, M. I. B. et al. Atividade antifúngica de extratos de plantas a Colletotrichum gloeosporioides. Acta Scientiarum, v.30, p. 1-5, 2008.

CELOTO, M. I. B. Atividade antifúngica de extratos de melão-são-caetano (Momordica charantia L.) sobre Colletotrichum musae (Berk. \& Curtis) Arx. 2005. Dissertação (Mestrado em área de concentração em Sistemas de Produção) - Universidade Estadual Paulista Júlio de Mesquita Filho, São Paulo, 2005.

CHAGAS, F. et al. Controle biológico em sistema orgânico de produção por agricultores da cidade de Maringá (Paraná, Brasil). Ciência e Natura, v. 38, p. 637-647, 2016.

1 Agradecemos ao Professor Doutor Henrique Von Hertwig Bittencourt pelo assessoramento com os tratamentos estatísticos. 
DEAN, R. et al. The top 10 fungal pathogens in molecular plant pathology. Mol. Plant Pathol., v. 13, p. 414-430, 2012.

FLECK, M. et al. Número cromossômico, comportamento meiótico e viabilidade de grãos de pólen em populações de Vasconcellea quercifolia A. St. Hill. (Caricaceae) nativas no Vale do Taquari. Rev. Eletr. Cient. Uergs, v.1, p.19-24, 2015.

GUPTA, M.; SHARMA, S.; BHADAURIA, R. In vitro efficacy of Momordica charantia extracts against phytopathogenic fungi, Fusarium oxysporum. J. Biopesticides, v. 9, p. 8-22, 2016.

KINUPP, V. F.; LORENZI, H. Plantas alimentícias não convencionais (PANC) no Brasil. São Paulo: IPEF, 2014.

O'DONNEL, K. et al. Phylogenetic analyses of RPB1 and RPB2 support a middle Cretaceous origin for a clade comprising all agriculturally and medically important fusaria. Fungal Gen. Biol., v. 52, p. 20-31, 2013.

PINOTTI, M. M. Z.; SANTOS, J. C. P. From the ancient times of the agriculture to the biological control in plants: a little of the history. Ciência Rural, v. 43, p. 1797-1803, 2013.

SILVA, K. M. et al. Qualidade sanitária e fisiológica da hortaliça não convencional Luffa acutangula. Horticult. Bras., v. 30, p. 8085-8090, 2012.

VENTUROSO, L. R. et al. Inibição do crescimento in vitro de fitopatógenos sob diferentes concentrações de extratos de plantas medicinais. Arq. Inst. Biol., v. 78, p. 89-95, 2011.

WANG, S. et al. Antifungal activity of Momordica charantia seed extracts toward the pathogenic fungus Fusarium solani L. J. Food Drug Anal., v. 24, p. 881-887, 2016.

WIDODO; SUPRAMANA. Fusarium species associated with corm rot of taro in Bogor. Microbiol. Indonesia, v. 5, p. 132-138, 2011.

ZHU, F. et al. The plant ribosome-inactivating proteins play importante roles in defense against pathogens and insect pest attacks. Front. Plant Sci., v.9, p. 1-14, 2018. 